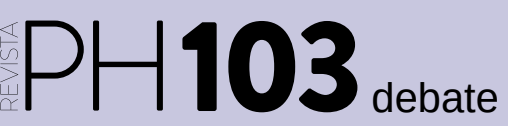

a debate Dilemas del arte urbano como patrimonio

| coordinan Elena García Gayo y Laura Luque Rodrigo

\title{
La patrimonialización del arte urbano. Posibilidades y condiciones
}

Diego García Viana | Grupo de investigación sobre Gestión del Patrimonio Cultural, Universidad Complutense de Madrid

URL de la contribución <www.iaph.es/revistaph/index.php/revistaph/article/view/4874>

El arte urbano ha comenzado a tener un reconocimiento social, institucional y artístico, aunque tradicionalmente el grafiti ha sido mal visto por la sociedad y los medios. Dicha visión peyorativa ha sido asumida, en ocasiones, por los profesionales del patrimonio cultural, que han visto cómo las manifestaciones en spray (vandalismo que no siempre es grafiti o arte urbano) han sido una amenaza y un problema para la conservación y la salvaguarda de diversos bienes, aunque a veces ha sido motivo para defender y unir ambos "mundos"1.

Para poder considerar al arte urbano como bien patrimonial, se debe precisar mejor su conceptualización y acercarlo al de patrimonio cultural, lo que supondría un mejor reconocimiento técnico que fomentaría su identificación y protección desde este campo de estudio. Desde la disciplina de bellas artes, o de la historia del arte, es evidente su reconocimiento, pero si se quiere pasar por el filtro del patrimonio cultural, se deberá tener en cuenta lo heredado y qué merece la pena ser conservado y protegido de ese arte urbano (Querol 2020, 11). Si lo entendemos así, para que se le considere patrimonio, el arte urbano debe generar una voluntad social de querer mantenerlo y un reconocimiento a través de la normativa para que tenga una protección jurídica.

En cuanto a la primera condición, el reconocimiento o la voluntad social depende muchas veces del tipo de arte urbano, de la persona artista, incluso de lo que represente la pieza, la actuación y/o el mural. Algunas obras dentro del arte público, fomentado y subvencionado por instituciones civiles y culturales, han tenido problemas de reconocimiento por parte de la comunidad, que han rechazado lo expresado, o su ubicación, hecho que también ocurre con actuaciones de preservación y restauración del patrimonio cultural. Si el arte urbano se realiza desde la práctica de arte relacional o contextual, teniendo en cuenta a la comunidad que ahí reside, se fomenta una correcta conjunción entre la voluntad de la comunidad y la creación del artista, dándose una plena aceptación social sobre dichas manifestaciones. Esto hará que dichas comunidades generen valores, memoria, cohesión e identidad en torno a este arte, dinámicas aceptadas desde el campo del patrimonio cultural (Consejo de Europa 2005).

En relación con el reconocimiento legal, aunque las leyes de propiedad intelectual son claras (Giner Cordero 2016, 29), este tipo de manifestación artística, por su origen e idiosincrasia, no busca un ordenamiento jurídico que lo limite, incluso los y las artistas y el público aprecian esta transgresión. En parte, en el patrimonio cultural, esto también ha ocurrido, sobre todo con los bienes inmateriales que se declaran, pues acotar algo que está "vivo" hace que no cambie en algunas de sus formas y genera conflictos dentro de las propias comunidades. A veces pasa también incluso con los bienes materiales, donde muchas comunidades ven objetos inamovibles e intocables con los que poco a poco pierden la conexión y se producen desapegos (Castillo, Yáñez y Domínguez 2016). Pese a las dificultades, que el arte urbano entre en los circuitos de legalización parece que puede ser una oportunidad para su mantenimiento y protección. Desde la perspectiva del arte público este paso a dar puede ser más sencillo y es evidente, por tanto, que el factor legal es clave para el reconocimiento y más desde la perspectiva occidental.

Por todo lo expuesto, el arte urbano, reconocido jurídicamente y valorado socialmente, puede ser un bien más dentro del patrimonio cultural. De hecho, ya tenemos ejemplos de patrimonialización. Por supuesto, para que 
se diera esta patrimonialización, se ha pasado primero por el reconocimiento de la obra, o en algunos casos del o la artista, y esto ha hecho que se generen protecciones diversas o acciones de conservación sobre estas manifestaciones, o al menos trabajos de documentación. Anteriormente, la pintura mural, "alejada" del arte urbano, ha sido protegida y conservada teniendo en cuenta su contexto y su relación con el bien inmueble donde fue realizada (Luque Rodrigo y Moral Ruiz 2020,60 ), pero otras veces ha habido casos de arranques murales para ser expuestos en museos². Quizá equiparar la pintura mural con el arte urbano sea una posible solución para algunas de las manifestaciones a nivel técnico a la hora de realizar dicha patrimonialización. El caso de la firma de Muelle, en la calle Montera de Madrid, puede ser un ejemplo de patrimonialización, aunque fue su historia y unicidad lo que determinó su protección y valoración, pese a que se consiguió que entrara como categoría BIC.

La patrimonialización del arte urbano quizá deba tener en cuenta factores que otros bienes no suelen tener, como la diversidad de manifestaciones, lo efímero y espontáneo, o lo ilegal; y por supuesto, la comunidad en que se desarrolla y a quién va dirigido o expresa. La consecuencia es que los procesos de patrimonialización de los bienes de arte urbano no serán homogéneos bajo un mismo criterio, y en muchas ocasiones todo dependerá de las características y las necesidades de la obra o la actuación.

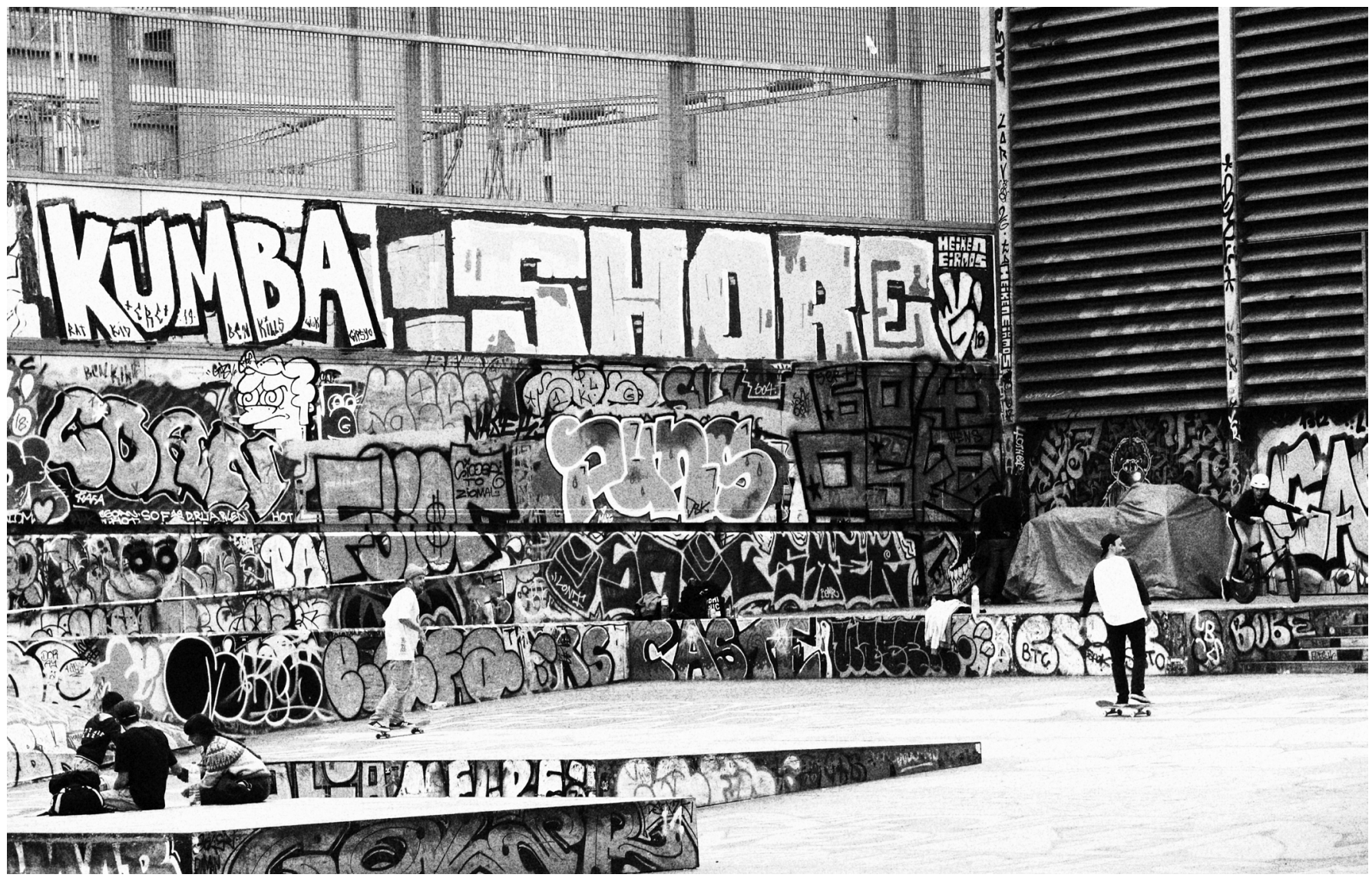

Jardins de les Tres Xemeneies (Barcelona). Zona de arte urbano sobre un antiguo paisaje industrial y urbano | foto Diego García Viana 
Está claro que este movimiento artístico es un catalizador de cambio en los paisajes urbanos e industriales, y a veces en los rurales, lugares muchas veces dejados y obviados por la sociedad que los habita o utilizó. Estos cambios en el paisaje pueden ser vistos como algo ajeno, antiestético, nocivo y que rompe el sentido paisajístico, pero se tienen que tener en cuenta, porque el arte urbano es ya una realidad, se quiera o no. Considerando que la opinión de las comunidades y creadores/as es determinante cuando se vaya a hacer un tipo de declaración patrimonial sobre este arte, es importante incluir también la de los y las profesionales del sector patrimonial, que deben considerar su gestión para una correcta conjunción con el resto de bienes patrimoniales, generando sinergias positivas y convirtiendo al arte urbano en un elemento más a tener en cuenta en el campo del patrimonio cultural.

\section{NOTAS}

1. Véase en este sentido el ejemplo de las jornadas organizadas con título "No nos toque el patrimonio. Vandalismo no es grafiti" en Menorca por el Consell Insular, l'Ajuntament de Ciutadella y el colectivo de grafiteros Menor Kings: www.menorcatalayotica.info/Contingut.aspx?ldPub=10124

2. En el Museo del Prado encontramos diferentes pinturas murales. Véase, por ejemplo, la ermita de la Vera Cruz de Maderuelo (www.museodelprado.es/coleccion/ obras-de-arte?search=pintura $\% 20$ mural $\% 20$ de $\% 20$ la\%20ermita\%20de\%20la\%20vera\%20cruz\%20de\%20 maderuelo.\&ordenarPor=pm:relevance).

\section{BIBLIOGRAFÍA}

- Castillo Mena, A., Yáñez, A., y Domínguez, M. (2016) Citizen perceptions about world heritage and archaeology in three Spanish cities: first methodological case studies. Complutum, vol. 27, n. ${ }^{\circ}$ 2, pp. 295-314. Disponible en: https://revistas.ucm. es/index.php/CMPL/article/view/54747 [Consulta: 23/03/2021]
- Consejo de Europa (2005) Convenio marco del consejo de Europa sobre el valor del patrimonio cultural para la sociedad (Faro, 27 de octubre de 2005). Serie Tratados del Consejo de Europa, n. ${ }^{\circ}$ 199. Disponible en: https://rm.coe.int/16806a18d3 [Consulta: 23/03/2021]

- Giner Cordero, E. (2016) Propiedad intelectual y arte urbano. Mural Street Art Conservation, n. ${ }^{\circ} 3$, pp. 28-31. Disponible en: https://issuu.com/observatoriodearteurbano/docs/mural_3 [Consulta: 23/03/2021]

- Luque Rodrigo, L. y Moral Ruiz, C. (2021) El arte urbano como patrimonio inmaterial. Posibilidades para su protección y difusión. En: I Simposio Anual De Patrimonio Natural y Cultural ICOMOS España. Valencia: Universitat Politècnica de València, pp. 57-64

- Querol, M.A. (2020) Manual de Gestión del Patrimonio Cultural. Madrid: Akal 